\title{
Evaluation of Ureteric Jet by Color Doppler Ultrasound in Pregnancy
}

\author{
HODA S. DARWISH, M.D. \\ The Department of Radio-Diagnosis, Faculty of Medicine, Suez Canal University, Egypt
}

\begin{abstract}
Background: Abdominal pain during pregnancy can be caused by many conditions related to diseases of abdomen, urinary system, gynecological and obstetric problems. One of the important conditions causing non obstetrical pain during pregnancy is renal colic. Ureteral jet is the phenomenon that seen when the dense urine from the ureter is expelled into the more dilute urine in the urinary bladder.
\end{abstract}

Aim of Study: Was to ass ureteric jet by color Doppler ultrasound in pregnant women.

Subjects and Methods: Total number of 75 pregnant patients with singleton pregnancy referred to our Radiology Department from Obstetrics and Gynecology Department, in their second and third trimester, presented with suspected urinary tract infections or hydronephrosis were included in our prospective study.

Renal and bladder grey scale and bladder color Doppler ultrasonography were performed; patient should be full bladder. Ureteral jet angle was also measured as the angle between the direction of the ureteral jet and intraureteral ridge. Patterns of the ureteric jet were also recorded. Doppler ultrasound of the bladder area was performed in a transverse plane while patient supine includes both ureteric orifices to visualize the bilateral ureteral jets and measures the angle. Number of ureteral jets was also recorded for a period of one minute to three minutes. Study was done also in the right and left lateral decubitus position and number of ureteral jets was also recorded for a period of one or three minutes. Right ureteral jets were recorded in left lateral decubitus position whereas left ureteral jets were recorded in the right lateral decubitus position. Renal Ultrasound was done to detect back pressure changes and its severity.

Results: We used Statistical Package for Social Sciences (SPSS) software version 10 for data assessment. Mean age of patients was $23 \pm 4$ years. Average gestation age was $26.02 \pm$ 2.56 weeks with minimum and maximum gestation age 21 and 33 weeks respectively. Mean number of ureteral jets seen in supine position at right side was $1.91 \pm 1.71$ with minimum and maximum number of jets 0 and 4 respectively. Most frequent number of jets was " 0 " and seen in 36 cases $(48 \%)$ of the patients.

Back pressure changes diagnosed in 52 patients $(69 \%)$ was unilateral in $41 / 52$ patients $(78 \%)$ and bilateral in $11 / 52$

Correspondence to: Dr. Hoda S. Darwish, E-Mail: darwish.hoda@yahoo.com cases $(22 \%)$. Right kidney back pressure changes were seen in 35 patients and left side 6 cases. Mean \pm SD ureteral jet angle was significantly greater in affected units with back pressure (67.9 \pm 16.5 degrees) than in non affected units (42.8 \pm 12.2 degrees, $p<0.0001$ ). A cutoff angle of 55 degrees or greater was detected in cases with mild back pressure changes in our study. A cutoff angle of 70 degrees or greater was associated with more severe back pressure changes (moderate to severe backpressure changes). Out of 75 patients, 33 cases showing no backpressure changes and the ureteral jet angle was less than 55 degree in both ureteric orifices.

Conclusion: Color/pulse-wave Doppler US is avery useful tool for demonstrating ureteral jets and provides its characterization. Change in scanning position from supine to right/left decubitus position to ass ureteric jet in pregnant patients will be helpful and we suggest further studies to evaluate our cutoff angles.

Key Words: Ureteral jets - Pregnancy - Color DopplerUltrasonography - Doppler waveform - Vesicoureteric reflux.

\section{Introduction}

URETERIC jets, the intravesical ureteral jets, first mentioned by Kalmon et al., [1], were visualized ultrasonographically and described as the echographic appearance of urine entering the bladder in 1981 by Dubbins et al., [2].

Color Doppler ultrasound indicates normal urine flow through ureteric orifices by demonstrating normal jets and suggests obstruction by showing absent jets or flow trickling [3]

The ureteric jets are found to have three phases: The initial phase of pulsed oozing or flattened type of Doppler Waveforms (DW), or in combination/alteration of the two types; then, the steady diuresis phase (the second phase) of uniform DW

\footnotetext{
Abbreviation:

US : Ultrasonography.

SPSS : Statistical Package for Social Sciences.

DW : Doppler Waveform.

SD : Standard Deviation.
} 
with nearly regular intervals; and finally, the third phase of uneven DW of irregular intervals [4,5].

In the steady phase of renal diuresis (the second phase), Doppler waveform of ureteric jets is inevitably of multiple peaks of urine ejaculation in the healthy subjects [4]. It has been seen that spectral doppler show the presence of six waveform patterns (monophasic, biphasic, triphasic, polyphasic, square and continuous) [6].

Abdominal pain during pregnancy can be caused by a wide range of conditions related to diseases of the abdomen, urinary system, and gynecological and obstetric problems. One of the important conditions causing non-obstetricalpain during pregnancy is renal colic [7]

Ultrasound is the most important imaging technique being readily available, portable and safe during pregnancy [8].

The difficulty in distinguishing between pathologic hydronephrosis and physiologic dilatation of the collecting system has much been resolved by demonstration of ureteral jets on color Doppler ultrasound [9].

The purpose of our present study was to assess the ureteric jet in pregnant women with color Doppler ultrasound.

\section{Subjects and Methods}

Our study is prospective study and was performed at Radiology Department of Dallah Hospital Riyadh, Saudi Arabia from February 2018 to September 2018.

A total number of 75 pregnant patients with singleton pregnancy referred to our Radiology Department from Obstetrics and Gynecology Department, in their second and third trimester, presented with suspected urinary tract infections or hydronephrosis were included in our study.

The age of included cases was range between 18 to 34 years. Exclusion criteria was patients having solitary kidney, history of urinary obstruction or previous urological surgery, patients with nephrolithiasis and patients with renal scarring.

Human ethics committee approval for this study was obtained from the institutional review board of our hospital.

Renal and bladder grey scale and color Doppler ultrasonography to urinary bladder area was performed to all included patients, with a $3.5 \mathrm{MHz}$ convex probe (HD II XE Ultrasound 2006, Philips medical system, Nederland B.V).

Before each examination, the procedure was explained to the patient. Renal ultrasound was done to detect backpressure changes and determine its severity (mild, moderate, and sever).

Before ultrasonographic observation of the intravesical ureteric jets of urine, adequate hydration of the kidneys is necessary.

The probe is placed over the suprapubic region to face the base of the bladder and orientate the slice of ureteric jetsof both sides.

Doppler ultrasound of the bladder area was performed in a transverse plane to include both ureteric orifices to visualize the bilateral ureteral jets and measures the angle.

For expression of the ureteric jet Doppler waveform, the sample-volume cursor is set at the ureteral orifice where the jet arises. DW of the ureteric jets are continuously recorded during the steady diuresis phase of urine ejaculation.

Ureteral jet angle was measured as the angle between the direction of the ureteral jet and intraureteral ridge. Patterns and numbers of the ureteric jet were also recorded. The number of ureteral jets was also recorded for a period of one minute to three minutes. The study was done also in the right and left lateral decubitus position and number of ureteral jets was also recorded for a period of one or three minutes. Right ureteral jets were recorded in left lateral decubitus position whereas left ureteral jets were recorded in the right lateral decubitus position.

\section{Statistical analysis:}

Data were evaluated by using Statistical Package for Social Sciences (SPSS) software version 10 for calculating percentages and frequencies.

\section{Results}

We included 75 pregnant patients in their second and third-trimester pregnancy; the mean age of patients was $23 \pm 4$ years. The average gestation age was $26.02 \pm 2.526$ weeks with minimum and maximum gestation age 21 and 33 weeks respectively.

The mean number of ureteral jets seen in supine position at the right side Fig. (1A), was $1.91 \pm 1.71$ with minimum and maximum number of jets 0 and 4 respectively. While the mean number seen at the 
left side was 2. 16 $\pm 136 \mathrm{Fig}$. (1B) with minimum and maximum no of jets 0 and 6 respectively.

Most frequent number of jets was " 0 " and seen in 36 cases (48\%) of the patients, 30 cases of them were at the right side and seen in 6 cases in the left side.

Backpressure changes diagnosed in 52 patients $(69 \%)$ was unilateral in $41 / 52$ patients $(78 \%)$ and bilateral in 11/52 cases (22\%). Right kidney back pressure changes were seen in 35 patients and left side 6 cases.

Mean \pm SD ureteral jet angle was significantly greater in affectedunits with backpressure $(67.9 \pm$ 16.5 degrees) than in non affected units $(42.8 \pm 12.2$ degrees, $p<0.0001)$. A cutoff angle of 55 degrees or greater was detected in cases with mild back-

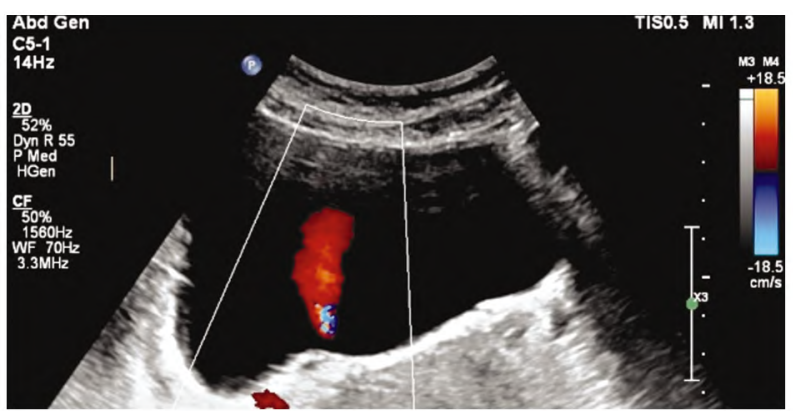

(A) pressure changes in our study. A cutoff angle of 70 degrees or greater was associated with more severebackpressure changes (moderate to severe backpressure changes).

Out of 75 patients, 33 cases showing no backpressure changes and the ureteral jet angle was less than 55 degree in both ureteric orifices.

Regarding ureteric jet Doppler waveform pattern was obtained in 39 cases (52\%) as follow; continuous Doppler waveform pattern was most common and seen in 16 cases Fig. (2A), while square Doppler waveform pattern seen in 11 cases Fig. (2B), polyphasic Doppler waveform pattern seen in 5 cases, and triphasic Doppler waveform pattern was seen in 3 cases. Biphasicand monophasic Doppler waveform pattern was seen in 2 and 2 cases respectively.

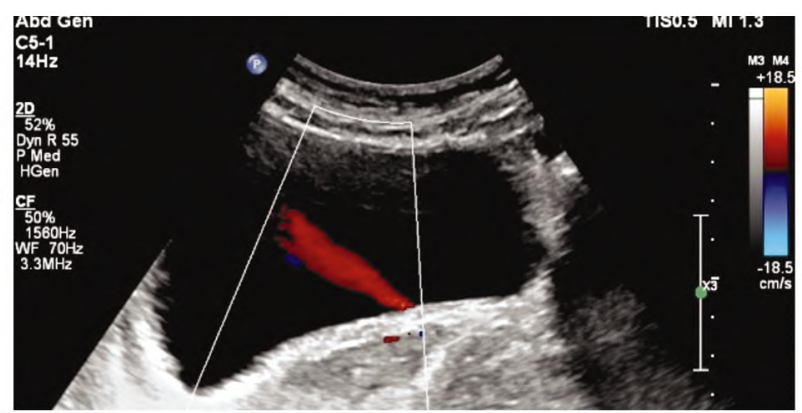

(B)

Fig. (1): Normal ureteric jets by color Doppler flow mapping in transverse scans at a suprapubic region. The ureteric arise from the right (A) Left (B) Side ureteral orifices and travel in an anteromedial direction across the midline.

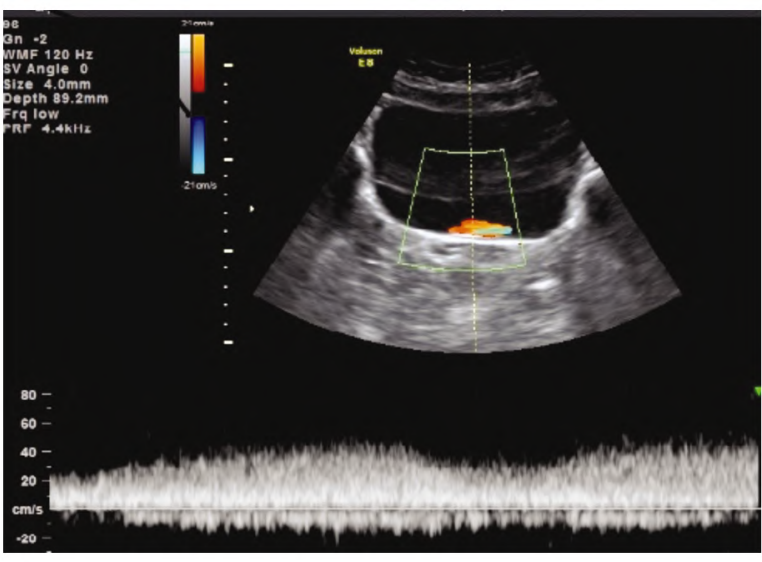

(A)

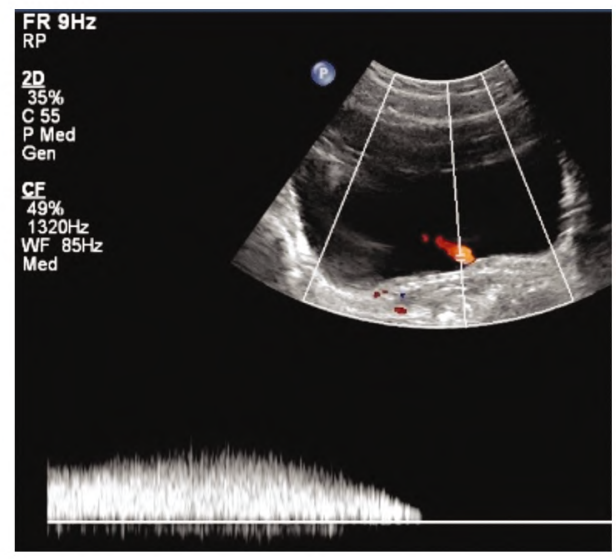

(B)

Fig. (2): Common Doppler waveform patterns of the ureteric jet: (A) Continuous Doppler waveform pattern of the ureteric jet. (B) Square Doppler waveform pattern of the ureteric jet.

\section{Discussion}

Ureteral jet is a phenomenon that is seen when the dense urine from the ureter is expelled into the more dilute urine in the urinary bladder.
In most healthy people, a ureteric jet frequency of two or more per minute on either side and the absence of ureteric jets during the 10 more minutes of observation in the steady dieresis phase,is con- 
sidered as a sign of complete obstruction [4-10], and the ureteric jet frequency of less than two per minute may indicate partial obstruction [4]

The normal urine flow through ureteric orifices can be demonstrated by color Dopplerultrasound and obstruction will be suggested by showing absent jets or flow trickling [11]

In our study, the most frequent number of jets was " 0 " and seen in 36 cases (48\%) of the patients in supine position, which is higher than some authors who showed that in healthy pregnant women the prevalence of absent ureteral jets on one side range from $3 \%$ to $15 \%$ [12]. Our results are close to the reported result in non-pregnant patients in which there is the unilateral absence of ureteral jets in $40 \%$ non-pregnant patients with renal dysfunction and normal jets on the other side [13]

This result may be due to our shorter scanning time in the supine position (1-3 minutes), however, we try to overcome that by doing right and left lateral decubitus positions and recorded the ureteric jet for a period of one to three minutes more for each. By doing that, more ureteric jet could be seen and the cases with (0) ureteral jet decreased from 36 cases $(48 \%)$ in a supine position to only 15 cases $(20 \%)$. Our result near the previously reported result suggested that the prevalence of absent ureteral jets on one side in healthy pregnant women range from $3 \%$ to $15 \%$ [12].

The (0) ureteric jet was seen more in the right side (29/36 cases) than left side (7/36 cases) in supine position ( $80 \%$ vs. $20 \%$ ) which may be due to the dextrorotation of the uterus, our result is close to the result of other literature [9-14] who reported the absenceof jets are more commonly seen on the right than on the left ( $85 \%$ vs. $15 \%)$.

The asymmetry of the ureteric jet that was seen is likely due to the physiological changes of pregnancy and changed uretero-dynamics during pregnancy owing to decreased smooth muscle tone and diminished peristalsis results in ureter being more flaccid with sluggish urine transit [15]

Limitation of our study was the relatively small number of patients; we suggest further studies with more sample size to increase the scopeof our findings and also to evaluate our results regarding the cutoff angles.

In conclusion, from our study, we found that color/pulse-wave Doppler US is a very useful tool for demonstrating ureteral jets and provides its characterization; and in some cases change the patient position from supine to right/left decubitus position toimprove visualization of the ureteric jet.

\section{References}

1- KALMON E.H., ALBERS D.D. and DUNN J.H.: Ureteral jet phenomenon: Stream of urination of the ureter. Radiology, 65: 933-5, 1995.

2- DUBBINS P.A., KURTZ A.B., DARBY J., et al.: Ureteric jet effect. The echographic appearance of urine entering the bladder. Radiology, 140: 513-5, 1981.

3- BURGE H.J., MIDDLETON W.D., McCLENNAN B.L. and HILDEBOLT C.F.: Ureteral jets in healthy subjects and in patients with unilateral ureteral calculi: Comparison with color Doppler US. Radiology, 180 (2): 437-42, 1991.

4- WU C.C.: The clinical application of Doppler waveforms of ureteric jets by color Doppler ultrasound. J. Intern. Med. Taiwan, 9: 12-8 [In Chinese], 1998.

5- HAN S.J., WU C.C., TSAI C.C., et al.: Ureteric jet in the assessment of renal function. J. Med. Ultrasound, 5: 458, 1997.

6- LEUNG V.Y., CHU W.C., YEUNG C.K. and METREWELI C.: Doppler waveforms of the ureteric jet: An overview and implications for the presence of a functional sphincter at the vesicoureteric junction. Pediatric Radiology, 37 (5): 417-25, 2007.

7- WOODFIELD C.A., LAZARUS E., CHEN K.C. and MAYO-SMITH W.W.: Abdominal pain in pregnancy: Diagnoses and imaging unique to pregnancy-review. A.J.R., 194 (6): 14-30, 2010.

8- PATEL S.J., REEDE D.L., KATZ D.S. and SUBRAMANIAM R.: Imaging the pregnant patient for nonobstetric conditions: Algorithms and radiation dose considerations1. Radiographics, 27 (6): 1705-22, 2007.

9- AWAN M.W., YAQUB W., ATHER S. and ABID A.: Evaluation of Ureteral Jets in Pregnancy by Colour Doppler: Effect of Patients' Position. Journal of Rawalpindi Medical College (JRMC), 19 (2): 136-9, 2015.

10- De BESSA Jr. J., DENES F.T., CHAMAS M.C., et al.: Diagnostic accuracy of color Doppler sonographic study of the ureteric jets inevaluation of hydronephosis. $\mathbf{J}$. Pediatr. Urol., 4: 113-7, 2008.

11- BURGE H.J., MIDDLETON W.D., McCLENNAN B.L. and HILDEBOLT C.F.: Ureteral jets in healthy subjects and in patients with unilateral ureteral calculi: Comparison with color Doppler US. Radiology, 180 (2): 437-42, 1991

12-ASRAT T., ROOSSIN M.C. and MILLER E.I.: Ultrasonographic detection of ureteral jets in normal pregnancy. Am. J. Obstet. Gynecol., 178 (6): 1194-98, 1998.

13- CHIU N.T., WU C.C., YAO W.J., TU D.G. and LEE B.F.: Evaluation and validation of ureteric jet index by glomerular filtration rate. Invest. Radiol., 34 (8): 499-502,1999.

14- RASMUSSEN P.E. and NIELSEN F.R.: Hydronephrosis during pregnancy: A literature survey. Eur. J. Obstet. Gynecol. Reprod Biol., 27 (3): 249-59, 1988.

15- SWANSON S.K., HEILMAN R.L. and EVERSMAN W.G.: Urinary tract stones in pregnancy. Surg. Clin. North Am., 75 (1): 123-42, 1995. 


\section{تقييم تلدق الحالب للمثانة بإستخدام الدوبلر الملون آثناء فترة الحمل}

هدف الدراسة: تهدف هذه الدراسة إلى تقييم تدفق الحالب للمثانة بإستخدام الدوبلر الملون آثناء فترة الحمل. الطريقة: تم إجراء هذه الدراسة على ه ع حالة من الحوامل فى المرحلة الثانية والثالثة من الحمل ممن يعانون من إلتهاب المسالك البولية

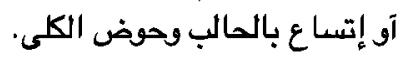

تم عمل فحص اللكى والمثانة وتحديد وجود آى تمدد فى الكلى وتقييم تدفق المالب للمثانة من حيث عد المرات وذاوية التدفق وذلك فى فترة

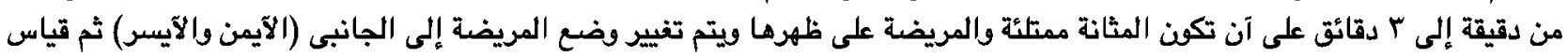
عدد مرات وذاوية التدفق مرة آخرى وذلك فئ في فترة من دقيقة إلى بـ دقائق.

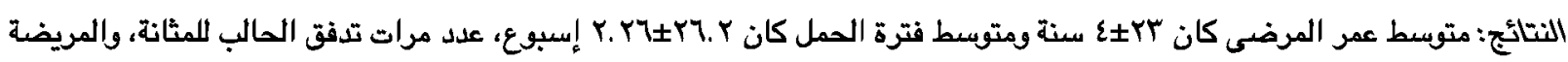

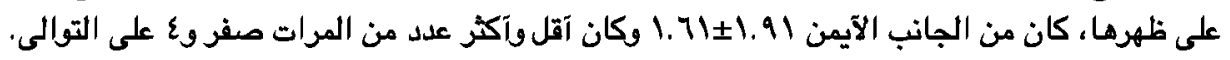

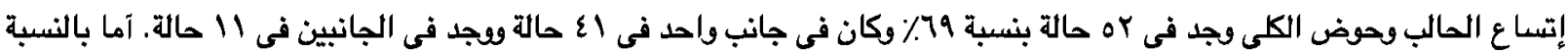

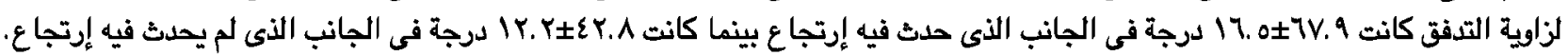
الخلاصدة: خلصب هذه الدراسة إلى آن الدوبلر الملون هو طريقة فعالة لتقييم تدفق الصالب للمثانة وتحديد خصائصه آثناء فترة الحمل. 